\title{
Diagnosis of pulmonary disease in human immunodeficiency virus infection: role of transbronchial biopsy and bronchoalveolar lavage
}

\author{
MH GRIFFITHS, G KOCJAN, RF MILLER, P GODFREY-FAUSSETT \\ From the Departments of Histopathology, Medicine and Cardiothoracic Surgery, University College and \\ Middlesex School of Medicine, London
}

ABSTRACT The value of transbronchial biopsy and bronchoalveolar lavage was assessed in the of diagnosis of pulmonary disease in patients infected with the human immunodeficiency virus (HIV).

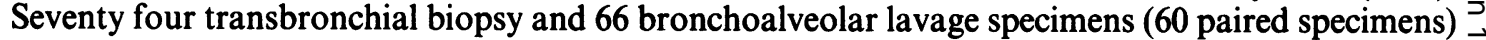
from 80 examinations in 64 patients were reviewed. Pneumocystis carinii was the most common $\subseteq$ pathogen isolated (43 patients). Bronchoalveolar lavage was superior to transbronchial biopsy for the $\rightleftharpoons$ diagnosis of this pathogen, the sensitivities being $90 \%$ and $56 \%$. Cytomegalovirus was identified $\vec{\bullet}$ three times by lavage and once by transbronchial biopsy. Neither method detected Kaposi's sarcoma in the one patient shown to have it by open lung biopsy. The complication rate in a concurrent study of bronchoscopy with transbronchial biopsy in 74 consecutive HIV positive patients was $22 \%$. This study does not support the use of transbronchial biopsy in these patients.

\section{Introduction}

Lower respiratory tract infection and pulmonary Kaposi's sarcoma are features of the acquired immune deficiency syndrome (AIDS), and are responsible for much of the morbidity and mortality from this condition. Bronchoscopy is commonly performed in the investigation of such patients. Bronchoalveolar lavage and transbronchial biopsy are often performed at bronchoscopy in the belief that this gives the best chance of establishing the cause or causes of the pulmonary infiltrate. The value of the two procedures in management and their contribution to morbidity need to be assessed so that efficient investigation is carried out. This is important because of limited resources and the rising incidence of AIDS - the number of cases of AIDS reported in the United Kingdom to the end of August 1988 was 1730, the number of new cases doubling every 11 months.'

\section{Methods}

Seventy four transbronchial biopsy specimens were reviewed histologically and 66 bronchoalveolar lavage

Address for reprint requests: Dr M H Griffiths, Department of Histopathology, Bland-Sutton Institute, Middlesex Hospital, London W1P 7PN.

Accepted 31 March 1989 specimens cytologically. The specimens were obtained from 80 bronchoscopic examinations performed at the Middlesex Hospital, London, from August 1986 to October 1988 on patients with human immunodeficiency virus (HIV) antibodies and with clinical evidence of lower respiratory tract disease. Only 60 paired transbronchial biopsy and lavage specimens, however, were available for comparison. Four open lung biopsy specimens were also reviewed. The 80 examinations had been carried out on 64 patients; some had repeated episodes of respiratory disease and investigations. The single female patient had a history of intravenous drug abuse three years previously. The remaining patients were male homosexuals.

Transbronchial biopsy specimens were taken with- 을 out fluoroscopic control, four specimens being obtain- $N$ ed on each occasion. For lavage, $180 \mathrm{ml}$ of warmed buffered saline* was instilled in $3 \times 60 \mathrm{ml}$ aliquots, $\tilde{N}$ usually into subsegments of the right lower lobe. A $\mathrm{\omega}$ return of $45-70 \%$ of the fluid instilled was achieved. Lavage fluid was divided for cytological and 0 microbiological studies. Biopsy specimens were for- $\overparen{D}$ malin fixed and prepared in routine fashion. They were $\stackrel{?}{+}$ examined after being stained with haematoxylin and 0 eosin, periodic acid-Schiff, Ziehl-Neelsen, and Grocott's silver methenamine.

Lavage specimens for cytological examination were $\stackrel{\mathbb{Q}}{\stackrel{Q}{2}}$ *Buffering: $0.75 \mathrm{ml}$ of $8.4 \% \mathrm{NaHCO}_{3}$ in 1 litre of normal saline $(0.9 \%)$. 
Table 1 Diagnoses from bronchoscopy and open lung biopsy specimens in 64 patients with human immunodeficiency virus antibodies

\begin{tabular}{|c|c|c|c|}
\hline \multirow[b]{2}{*}{ Diagnosis } & \multicolumn{2}{|c|}{ Bronchoscopy $(n=80)$} & \multirow{2}{*}{$\begin{array}{l}\text { Open } \\
\text { lung biopsy } \\
(n \cdot: 4)\end{array}$} \\
\hline & $\begin{array}{l}\text { Transbronchial } \\
\text { biopsy }(n=74)\end{array}$ & $\begin{array}{l}\text { Lavage } \\
(n=66)\end{array}$ & \\
\hline $\begin{array}{l}\text { Pneumocystis } \\
\text { Cytomegalovirus } \\
\text { Mycobacteria } \\
\text { Kaposi's sarcoma } \\
\text { Actinomycosis }\end{array}$ & $\begin{array}{c}30 \\
1 \\
1 *\end{array}$ & $\begin{array}{r}34 \\
3\end{array}$ & $\begin{array}{l}1^{*} \\
1\end{array}$ \\
\hline
\end{tabular}

*Granuloma.

received in sealed centrifuge tubes and processed in a room designated for AIDS related pathology, the safety procedures for category $\mathrm{Bl}$ organisms ${ }^{2}$ being followed. The fluid was centrifuged $(1500 \mathrm{rev} / \mathrm{min}$ for five minutes). Deposit was spread on glass slides with disposable forceps. Slides were air dried and then alcohol fixed and left in alcohol for 15-20 minutes for decontamination before staining by the Papanicolaou and May-Grünwald-Giemsa methods. Most specimens were also stained with silver methenamine and Ziehl-Neelsen stains.

In a separate but concurrent study ${ }^{3}$ (including many of the same patients) we examined the complication rate in 93 consecutive HIV antibody positive patients undergoing bronchoscopy with transbronchial biopsy and lavage (74) or lavage alone (19) for respiratory problems. All patients had a normal platelet count and normal results in clotting studies.

\section{Results}

A specific pathological diagnosis was made on 50 occasions from 84 diagnostic procedures (bronchoscopy plus open lung biopsy). Pneumonia due to Pneumocystis carinii was diagnosed on 43 out of 50 occasions. Cytomegalovirus infection was diagnosed on three occasions, and mycobacterial infection twice; actinomycosis and Kaposi's sarcoma were each diagnosed once. All pneumocystis and cytomegalovirus infections were diagnosed by bronchoscopic examination. Mycobacterial infection and Kaposi's sarcoma were diagnosed by open lung biopsy (table 1).

\section{PNEUMOCYSTIS PNEUMONIA}

The relative sensitivities of transbronchial biopsy and cytological examination of lavage specimens were compared in 60 cases in which paired specimens had been obtained at the same bronchoscopic examination (table 2). Pneumocystis pneumonia was diagnosed in 39 patients; lavage gave a positive result in 32 cases, whereas transbronchial biopsy was positive in only 22 cases $(56 \%)$. In only one case was $P$ carinii diagnosed from a transbronchial biopsy specimen when cytological examination had failed to show it. These figures include 16 transbronchial biopsy specimens considered technically "unsatisfactory" because of the small quantity of alveolar tissue obtained; $\boldsymbol{P}$ carinii was found in two of these specimens. A further three cases of pneumocystis infection were diagnosed by microbiological examination of lavage fluid. In three patients in whom both transbronchial biopsy and lavage had given negative results a diagnosis of pneumocystis infection was made subsequently-on the grounds of clinical suspicion and response to treatment in two and at necropsy in one. Overall, the sensitivity was $90 \%$ for lavage and $56 \%$ for transbronchial biopsy.

\section{CYTOMEGALOVIRUS INFECTION}

Cytomegalovirus inclusion bodies were detected in three lavage specimens, two being obtained from the same patient before and after treatment. In both cases the transbronchial biopsy specimen had been reported as negative, but serial sectioning and review after the cytological results were known led to the detection of cells with characteristic inclusion bodies. In the second case cytomegalovirus inclusion bodies were found in both the biopsy specimen and the lavage fluid. In none of the biopsy specimens was any appreciable "pneumonia" present. The patients' symptoms were related to cerebral and ocular cytomegalovirus infection. No concurrent infection with cytomegalovirus and pneumocystis was found.

\section{MYCOBACTERIAL INFECTION}

Careful examination of specimens failed to detect acid fast bacilli. One transbronchial biopsy specimen contained a poorly formed granuloma, possibly mycobacterial in origin, and in one open biopsy specimen a caseating granuloma was present, presumed to be mycobacterial; culture of fluid and lung tissue from both these patients was negative.

\section{ACTINOMYCOSIS}

Actinomycosis was identified in one lavage specimen but it was not seen in the corresponding transbronchial biopsy specimen.

Table 2 Diagnosis of Pneumocystis carinii pneumonia from 60 paired transbronchial biopsy $(T B B)$ and bronchoalveolar lavage fluid $(B A L)$ specimens

\begin{tabular}{llll}
\hline & $\begin{array}{l}\text { TBB } \\
\text { (histology) }\end{array}$ & $\begin{array}{l}\text { BAL } \\
\text { (cytology) }\end{array}$ & $\begin{array}{l}\text { Combined } \\
\text { TBB and BAL }\end{array}$ \\
\hline Positive & 22 & 32 & 33 \\
Negative* & 38 & 28 & 27 \\
Total & 60 & 60 & 60 \\
\hline
\end{tabular}

* Six patients with negative results from transbronchial biopsy and bronchoalveolar lavage had pneumocystis pneumonia diagnosed by other means (3), by the response to treatment (2), or at necropsy (1). 


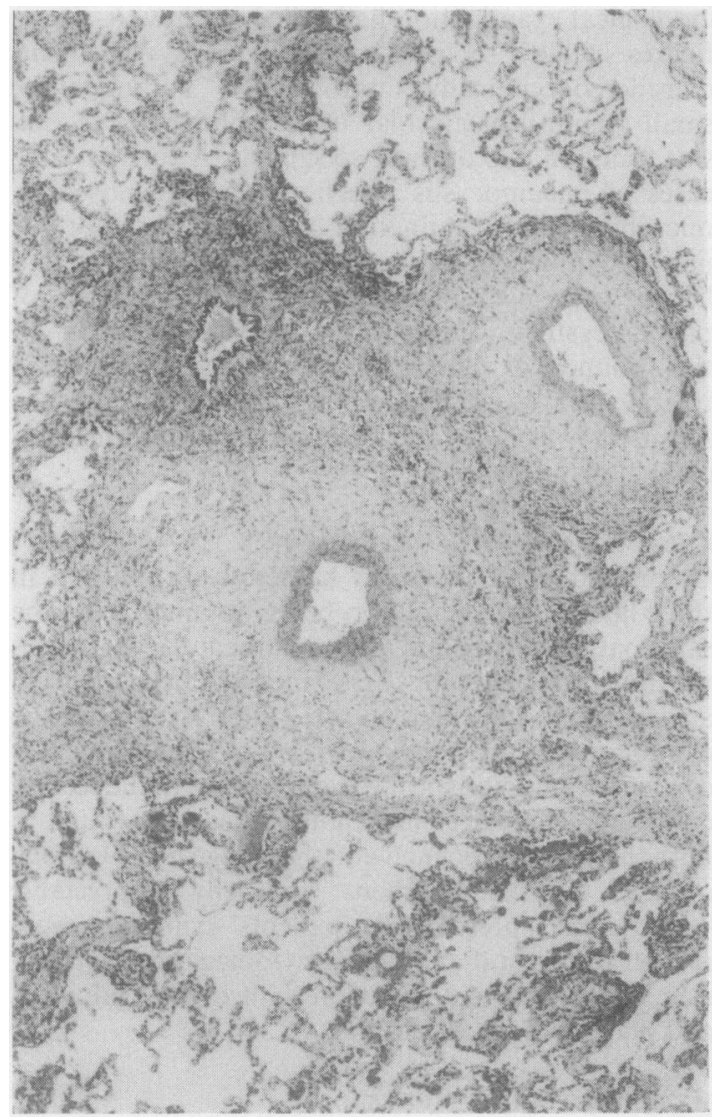

(a)

\section{KA POSI'S SARCOMA}

Extensive Kaposi's sarcoma was found in one patient from open lung biopsy (figure). The patient, who had cutaneous Kaposi's lesions, had had two transbronchial biopsies with negative results. Immunostaining for the endothelial markers factor VIII antigen and Ulex europaeus lectin binding was unhelpful. Open lung biopsy showed the Kaposi's sarcoma to be infiltrating interlobular septa, pleura, and peribronchial and perivascular tissues (figure, $a$ ). An unusual feature was the dense collagenous sclerosis between the ectatic vascular spaces, which were similar in other respects to those of the "patch" stage of cutaneous Kaposi's sarcoma (figure, $b$ ). In only a few areas were "nodular" lesions found. The sclerosis may have been secondary to hilar lymphatic obstruction by Kaposi's sarcoma.

\section{COMPLICATIONS}

The complication rate for the 74 bronchoscopies with concurrent transbronchial biopsy was $22 \%$. This included 15 episodes of pneumothorax, eight of which

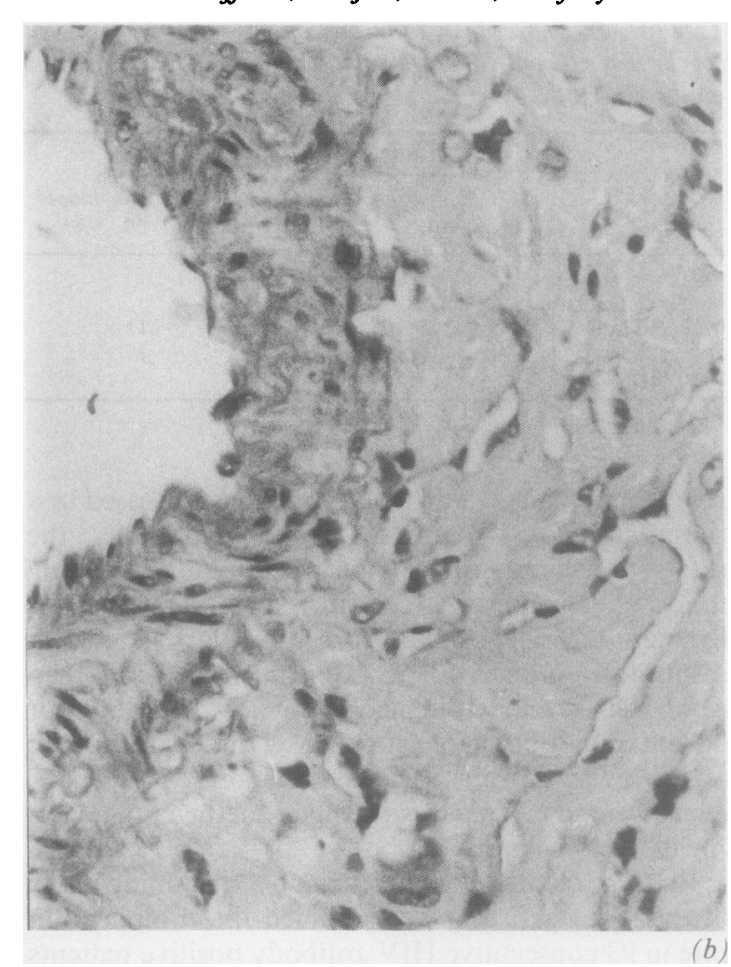

Pulmonary Kaposi's sarcoma: (a) low power view showing expansion of perivascular and peribronchiolar connective tissue by Kaposi's tissue; (b) high power view showing the characteristic angular endothelial lined spaces of Kaposi's sarcoma separated by hyalinised collagen, an unusual feature.

required a chest drain, and two cases of profuse haemorrhage, one of which was fatal. Pneumothorax occurred in $14(27 \%)$ of 52 patients with pneumocystis infection compared with one in the 22 without pneumocystis infection. The only complication in the 19 patients having lavage alone was bronchial wall oozing in two cases.

\section{Discussion}

Bronchoscopy is performed in HIV infected patients with clinical evidence of lower respiratory tract disease $c$ to provide bronchoalveolar lavage fluid for microbiological and cytological investigations, and to 0 provide transbronchial biopsy specimens for his- $\Phi$ tological examination. The airways may be examined $\stackrel{\mathcal{P}}{+}$

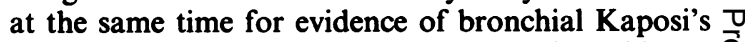
sarcoma. In some centres transbronchial biopsy specimens are used to make touch preparations for $\cong$ cytological assessment as well as for histological $\stackrel{\mathbb{Q}}{\complement}$ examination. The aim is to detect opportunist infection and pulmonary Kaposi's sarcoma so that specific 
treatment may be given or, in patients in whom a pathological diagnosis has already been established, to determine the response to treatment. In addition, detecting these conditions to establish the diagnosis of AIDS in a patient known to have HIV antibodies may be important. Non-opportunist infections, also common in these patients, ${ }^{4-6}$ may be diagnosed in this way, as may incidental inflammatory and neoplastic processes.

Pneumocytis carinii was the most common organism identified, as in other series based on biopsy or cytology. In two postmortem studies, ${ }^{78}$ however, cytomegalovirus was the most commonly identified pathogen.

We found bronchoalveolar lavage superior to transbronchial biopsy for detecting $P$ carinii. Other series have found a similar high sensitivity for bronchoalveolar lavage ${ }^{9-11}-95 \%$ in 20 cases in which lavage findings were compared with necropsy." Broaddus et al, ${ }^{12}$ however, reported a high sensitivity for both transbronchial biopsy and bronchoalveolar lavage $(93 \%$ and $89 \%)$ in 117 paired specimens; whereas a collective review of 141 cases recorded a sensitivity of only $79 \%$ for the cytological detection of $P$ carinii. ${ }^{13}$ Variations in technique, such as bronchial washing rather than bronchoalveolar lavage, may account for the reported lower sensitivity of cytology. A sensitivity of only $79 \%$ for cytology and $85 \%$ for transbronchial biopsy in paired specimens has also been reported, but the figure for cytology appears to include touch preparations from transbronchial biopsy as well as bronchoalveolar lavage specimens and this may explain the lower yield. ${ }^{14}$ It is not surprising that bronchoalveolar lavage is more effective than transbronchial biopsy for detecting pneumocystis infection, as the organisms lie almost entirely within the alveolar space and the alveolar content of at least $50 \mathrm{~cm}^{3}$ of lung is sampled during lavage, compared with less than $1 \mathrm{~cm}^{3}$ by transbronchial biopsy.

In our two patients with cytomegalovirus infection bronchoalveolar lavage was superior to transbronchial biopsy in identifying cytomegalovirus inclusion bodies. Culture is superior to both ${ }^{1516}$ but takes longer. The detection of early antigen by the fluorescent foci test (DEAFF) in bronchoalveolar lavage fluid rapidly identifies cytomegalovirus shedding but gives no indication of cytomegalovirus cytopathology. The meaning of a positive DEAFF test in these patients is still being evaluated. The incidence of cytomegalovirus infection in postmortem studies ${ }^{78}$ is very much higher than in antemortem series. Most cells showing the pathological features of cytomegalovirus infection appear to lie free within the alveolar space and bronchoalveolar lavage would be expected to give a higher yield than transbronchial biopsy. The importance of finding pulmonary cells infected with cyto- megalovirus is that disease in other tissues less accessible to biopsy (brain, eye) may then be attributed to cytomegalovirus. Pulmonary infection alone is rarely an indication for treatment.

Acid fast bacilli were not detected by bronchoalveolar lavage or transbronchial biopsy in this study. Infection with Mycobacterium tuberculosis is common in intravenous drug users with AIDS, ${ }^{17}$ but the lungs are less often affected than other organs. ${ }^{17-19}$

Kaposi's sarcoma was not identified by the two transbronchial biopsies from a patient in whom it was diagnosed by open lung biopsy. Bronchial Kaposi's sarcoma is easily identified bronchoscopically and in bronchial biopsy specimens, ${ }^{20}$ but parenchymal Kaposi's sarcoma is difficult to diagnose by transbronchial biopsy, ${ }^{21}$ though haemosiderin deposits and haemorrhage may give grounds for suspicion. Open lung biopsy is usually necessary to make the diagnosis in life, ${ }^{22}$ but it may also fail to show tumour in life..$^{23-25}$ Kaposi's sarcoma has been diagnosed by transbronchial biopsy. ${ }^{1426}$

Transbronchial biopsy did not contribute appreciably to the diagnosis of lower respiratory tract disease in our HIV infected patients. Histological examination provides information about the nature of the cellular infiltrate and its extent in the small piece of lung parenchyma sampled. It might suggest a diagnosis such as non-specific interstitial pneumonitis, ${ }^{27}$ but the therapeutic implications of this information are negligible. Among 10 patients with a diagnosis of non-specific interstitial pneumonitis from transbronchial biopsy, a specific diagnosis was found in seven at open lung biopsy. ${ }^{22}$ We confirmed that bronchoalveolar lavage was useful in diagnosing pneumocystis pneumonia. The cytological technique requires care but no particular expertise or experience. Neither bronchoalveolar lavage nor transbronchial biopsy was very successful in identifying cytomegalovirus infection.

Our complication rate of $22 \%$ in patients having transbronchial biopsy was due to the high incidence of pneumothorax, mainly in patients with pneumocystis infection. This compares with reported pneumothorax rates of 9-19\% for transbronchial biopsy, ${ }^{128-30}$ which is greater than for bronchoscopy alone. ${ }^{31}$ Fluoroscopic control made no difference to the complication rate of transbronchial biopsy in a series of 250 bronchoscopies in patients with AIDS. ${ }^{32}$ Transbronchial biopsy in these patients is difficult to justify because the small contribution made to diagnosis was offset by the complications associated with it.

We thank Professor S J G Semple, Dr N McI Johnson, and $\mathrm{Mr} \mathrm{T}$ Treasure, whose patients were studied, for helpful criticism and discussion and Hilary Hannam for preparing the manuscript. 


\section{References}

1 McCormick A, Tillett H, Bannister B, Emslie J. Surveillance of AIDS in the United Kingdom. Br Med J 1987; 295:1466-9.

2 Department of Health and Social Security. Code of practice for the prevention of infection in clinical laboratories and post-mortem rooms. London: HMSO, 1985.

3 Miller RF, Millar AB, Semple SJG. Complications of fibreoptic bronchoscopy in HIV-1 antibody positive patients undergoing investigations for pulmonary disease [abstract]. Thorax 1988;43:847.

4 White S, Tsou E, Waldhorn RE, Katz P. Life threatening bacterial pneumonia in male homosexuals with laboratory features of the acquired immunodeficiency syndrome. Chest 1985;87:486-8.

5 Polsky B, Gold JWM, Whimbrey E, et al. Bacterial pneumonia in patients with the acquired immunodeficiency syndrome. Ann Intern Med 1986;104:38-41.

6 Witt DJ, Craven DE, McCabe WR. Bacterial infections in adult patients with the acquired immune deficiency syndrome (AIDS) and AIDS-related complex. Am J Med 1987;82:900-6.

7 Nash G, Fligiel S. Pathologic features of the lung in the acquired immune deficiency syndrome (AIDS): An autopsy study of seventeen homosexual males. Am J Clin Pathol 1984;81:6-12.

8 Hui AN, Koss MN, Meyer PR. Necropsy findings in acquired immunodeficiency syndrome. A comparison of premortem diagnoses with postmortem findings. Hum Pathol 1984;15:670-6.

9 Orenstein M, Webber CA, Cash M, Heurich AE. Value of bronchoalveolar lavage in the diagnosis of pulmonary infection in acquired immune deficiency syndrome. Thorax 1986;41:345-9.

10 Golden JA, Hollander H, Stulbarg MS, Gamsu G. Bronchoalveolar lavage as the exclusive modality for Pneumocystis carinii pneumonia. Chest 1986;90:18-22.

11 Gal AA, Klatt EC, Koss MN, Strigle SM, Boylen CT. The effectiveness of bronchoscopy in the diagnosis of Pneumocystis carinii and cytomegalovirus pulmonary infections in acquired immunodeficiency syndrome. Arch Pathol Lab Med 1987;111:238-41.

12 Broaddus C, Dake MD, Stulbarg MS, et al. Bronchoalveolar lavage and transbronchial biopsy for the diagnosis of pulmonary infections in the acquired immunodeficiency syndrome. Ann Intern Med 1985; 102:747-52.

13 Murray JF, Felton CP, Garay SM, et al. Pulmonary complications of the acquired immunodeficiency syndrome. Report of the National Heart, Lung and Blood Institution workshop. $N$ Engl J Med 1984;310:1683-8.

14 Francis ND, Goldin RD, Forster SM, et al. Diagnosis of lung disease in acquired immune deficiency syndrome: biopsy or cytology and implications for management. $J$ Clin Pathol 1987;40:1269-73.

15 Blumenfeld W, Wagar E, Hadley WK. Use of the transbronchial biopsy for the diagnosis of opportunistic pulmonary infections in acquired immunodeficiency syndrome (AIDS). Am J Clin Pathol 1984; 81:1-5.

16 McKenna RJ, Campbell A, McMurtrey MJ, Mountain CF. Diagnosis for interstitial lung disease in patients with acquired immunodeficiency syndrome (AIDS): a prospective comparison of bronchial washing, alveolar lavage, transbronchial lung biopsy and open-lung biopsy. Ann Thorac Surg 1986;41:318-21.

17 Sunderam G, McDonald RJ, Maniatis T, Oleske J, Kapila R, Reichman LB. Tuberculosis as a manifestation of the acquired immunodeficiency syndrome (AIDS). JAMA 1986;256:362-6.

18 Pitchenik AE, Cole C, Russell BW,Fischl M, Spira TJ, Snider DE. Tuberculosis, atypical mycobacteriosis and the acquired immunodeficiency syndrome among Haitian and non-Haitian patients in South Florida. Ann Intern Med 1984;101:641-5.

19 Stover DE, White DA, Romano PA, Gellene RA, Robeson WA. Spectrum of pulmonary diseases associated with the acquired immune deficiency syndrome. Am J Med 1985;78:429-37.

20 Fouret PJ, Touboul JL, Maynaud CM, Akoun GM, Roland J. Pulmonary Kaposi's sarcoma in patients with acquired immune deficiency syndrome: a clinicopathological study. Thorax 1987;42:262-8.

21 Ogbinene FP, Steis RG, Macher AM, et al. Kaposi's sarcoma causing pulmonary infiltrates and respiratory failure in the acquired immunodeficiency syndrome. Ann Intern Med 1985;102:471-5.

22 Pass HI, Potter D, Shelhammer J, et al. Indications for and diagnostic efficacy of open-lung biopsy in the patient with the acquired immunodeficiency syndrome (AIDS). Ann Thorac Surg 1986;41:307-12.

23 Garay SM, Belenko M, Fazzini E, Schinella R. Pulmonary manifestitations of Kaposi's sarcoma. Chest 1987; 91:39-43.

24 Meduri GU, Stover DE, Lee M, Myskowski PL, Caravelli JF, Zanman MB. Pulmonary Kaposi's sarcoma in the acquired immune deficiency syndrome. $\mathrm{Am}$ J Med 1986;81:11-8.

25 Nash G, Fligiel S. Kaposi's sarcoma presenting as pulmonary disease in the acquired immunodeficiency syndrome: diagnosis by lung biopsy. Hum Pathol 1984; 15:999-1001.

26 Hanson PJV, Harcourt-Webster JN, Gazzard BG, Collins JV. Fibreoptic bronchoscopy in the diagnosis of broncho-pulmonary Kaposi's sarcoma. Thorax 1987;42:269-71.

27 Suffredini AF, Ognibene FP, Lack EE, et al. Non-specific interstitial pneumonitis: a common cause of pulmonary disease in the acquired immunodeficiency syndrome. Ann Intern Med 1987;107:7-13.

28 Cunningham JH, Zavala DC, Corry RJ, Keim LW. Trephine air drill, bronchial brush and transbronchial $\Omega$ lung biopsies in immunosuppressed patients. Ann Rev N Respir Dis 1977;115:213-20.

29 Feldman NT, Pennington JE, Ehriem G. Transbronchial lung biopsy in the compromised host. JAMA 1977;238: 1377-9.

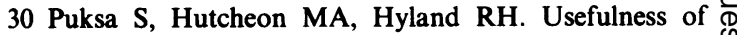
transbronchial biopsy in immunosuppressed patients with pulmonary infiltrates. Thorax 1983;30:146-50.

31 Simpson FG, Arnold AG, Purvis A, Belfield PW, Muers MF, Cook NJ. Postal survey of bronchoscopic practice $\overparen{\Phi}$ by physicians in the United Kingdom. Thorax 1986;41: 311-7.

32 Milligan SA, Luce JM, Golden J, Stulbarg M, Hopewell PC. Transbronchial biopsy without fluoroscopy in $尺$ patients with diffuse Reontgengraphic infiltrates and AIDS. Am Rev Respir Dis 1988;137:486-8. 